\title{
Application of Originally Designed Polymer Micro-Shunt in Open-Angle Glaucoma Surgery
}

\author{
DOI: 10.17691/stm2015.7.2.18
}

Received December 13, 2014

Y.A. Maslennikova, PhD Student, Department of Eye Diseases";

G.S. Bogdanov, PhD, Assistant, Department of Eye Diseases ${ }^{1}$;

A.A. Lankina, Clinical Resident, Department of Eye Diseases";

I.G. Smetankin, MD, DSc, Head of the Department of Eye Diseases ${ }^{1}$; Director of Eye Clinic ${ }^{2}$

${ }^{1}$ Nizhny Novgorod State Medical Academy, Minin and Pozharsky Square, 10/1 Nizhny Novgorod, 603005, Russian Federation;

${ }^{2}$ Nizhny Novgorod Regional Clinical Hospital named after N.A. Semashko, 190 Rodionova St., Nizhny Novgorod, 603126, Russian Federation

The aim of the investigation was to assess the efficiency of the original polymer micro-shunt application in open-angle glaucoma surgery.

Materials and Methods. 31 open-angle glaucoma patients (31 eyes) with elevated intraocular pressure (IOP) were followed up in our clinic. Of them 16 patients (16 eyes) suffered from glaucoma stage III, 14 (14 eyes) stage IV, 1 patient from stage II. Visual acuity varied from 0.2 (with or without correction) to abnormal light projection. Initial IOP was $27-38 \mathrm{~mm} \mathrm{Hg}$. All patients underwent partial deep sclerectomy with implantation of the patented polymer micro-shunt. The control group included 29 patients who underwent standard sinus trabeculectomy. Visual acuity varied from 0.5 to normal light projection, IOP was from $28-40 \mathrm{~mm} \mathrm{Hg}$.

Results. In early postoperative period the patients of both groups showed a marked hypotensive effect. However, IOP below $20 \mathrm{~mm} \mathrm{Hg}$ was sustained in the main group throughout the whole follow-up period, while $35.4 \%$ of patients in the control group required hypotensive therapy already 9 months after the surgery. Evaluation of visual function dynamics data revealed better stabilization process in the main group. According to the results of computed threshold perimetry, negative dynamics was observed in $13.3 \%$ of cases in the main group and $28.3 \%$ in the control group. The number of postoperative complications was lower in the main group, caused, as a rule, by initial severity of the disease. The total number of complications in the control group was $5(16.1 \%)$, and $11(37.9 \%)$ in the main group.

Conclusion. Application of the original micro-shunt in antiglaucomatous surgery provides long-term steady hypotensive effect and stabilizes visual functions, making this method a promising one for surgical treatment of open-angle glaucoma patients.

Key words: glaucoma; ophthalmosurgery; micro-shunt for antiglaucomatous surgery.

Surgical treatment of glaucoma has occupied first place in the recent years, and in a number of cases it is the method of choice even when revealed for the first time. The experience gained by the Eye Clinic of Nizhny Novgorod Regional Clinical Hospital named after N.A. Semashko shows, that more than $50 \%$ of patients with glaucoma who sought medical aid in 20132014 required surgical treatment.

At present, special attention is paid to glaucoma drainage surgery. There is a wide variety of drainage devices available for eye surgeons, but there are no reliable data to confirm the advantages of this or that model [1-3]. Nowadays micro-shunting is widely used at the first stage of surgical treatment in primary openangle glaucoma patients [4]. However, drainage surgery has certain disadvantages. The materials used for these devices are frequently far from ideal: they are heavy and tend to cut and acidize. Specific characteristics and complications of well-known implanted glaucoma shunts are described in a number of papers by foreign and Russian authors [5-7]. Inadequate shunt position makes reimplantation rather complicated, traumatic and requires special surgical equipment $[6,7]$. Search for the solution of these problems leads to the development of new technologies.

The aim of the investigation was to assess the efficiency of the original polymer micro-shunt application in open-angle glaucoma surgery.

Materials and Methods. 31 open-angle glaucoma patients (31 eyes) with elevated intraocular pressure (IOP) aged 16 to 82 years were followed-up in our clinic. Of them 23 patients (23 eyes) had simple primary openangle glaucoma, 5 patients (5 eyes) pseudoexfoliative open-angle glaucoma, 3 patients ( 3 eyes) secondary open-angle glaucoma. 16 patients (16 eyes) suffered from glaucoma stage III, 14 (14 eyes) - stage IV. One patient with stage II underwent micro-shunt implantation in the course of a single-step surgical intervention for vitreal block developed after YAG-laser capsulotomy, where the first step required anterior vitrectomy and peripheral iridectomy. Visual acuity varied from 0.2 (with or without correction) to abnormal light projection, initial

For contacts: Maslennikova Yuliya Alexandrovna, e-mail: ju.a.maslennikova@yandex.ru 
IOP level was $27-38 \mathrm{~mm} \mathrm{Hg}$. All patients underwent partial deep sclerectomy with implantation of the original polymer micro-shunt.

For control we used a group of 29 patients who underwent standard sinus trabeculectomy and included 21 patients with glaucoma stage III, 6 patients with stage II, 2 patients with stage IV. Visual acuity varied from 0.5 to normal light projection, IOP was $28-40 \mathrm{~mm} \mathrm{Hg}$.

The micro-shunt [8] is made of oligo carbonate methacrylate and represents a square hollow tube $2.5 \mathrm{~mm}$ long, with $0.5 \mathrm{~mm}$ diameter and $0.2 \mathrm{~mm}$ diameter of the inner hole. The needle cutoff angle is $45^{\circ}$. At the needle point there are two additional lateral anti-lock openings $0.15 \mathrm{~mm}$ in diameter. The micro-shunt consists of two parts: the needle, which is placed in the anterior chamber, and supporting elements to fix between the surface flap and the deep layers of sclera (Figure 1). The shunt is manufactured by Reper NN company (Nizhny Novgorod, Russia).

Before the operation and in the postoperative period all patients were subject to complex examination including visometry, Maklakov tonometry, electronic tonometry and tonometric testing with GlauTest-60 device (Russia). The patients with preserved visual functions also underwent
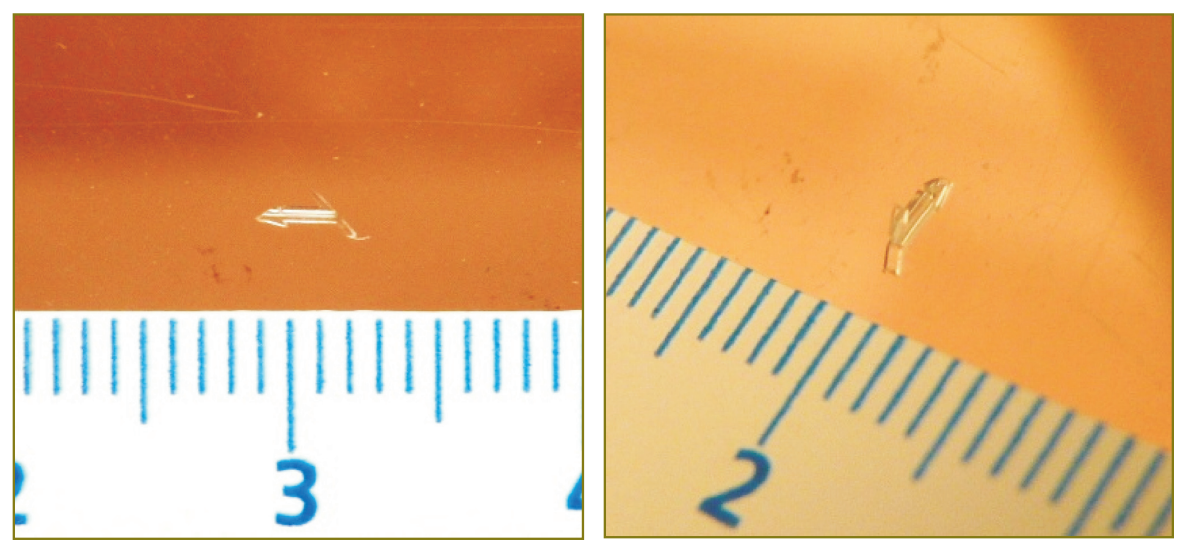

Figure 1. Original glaucoma microshunt, model C-1
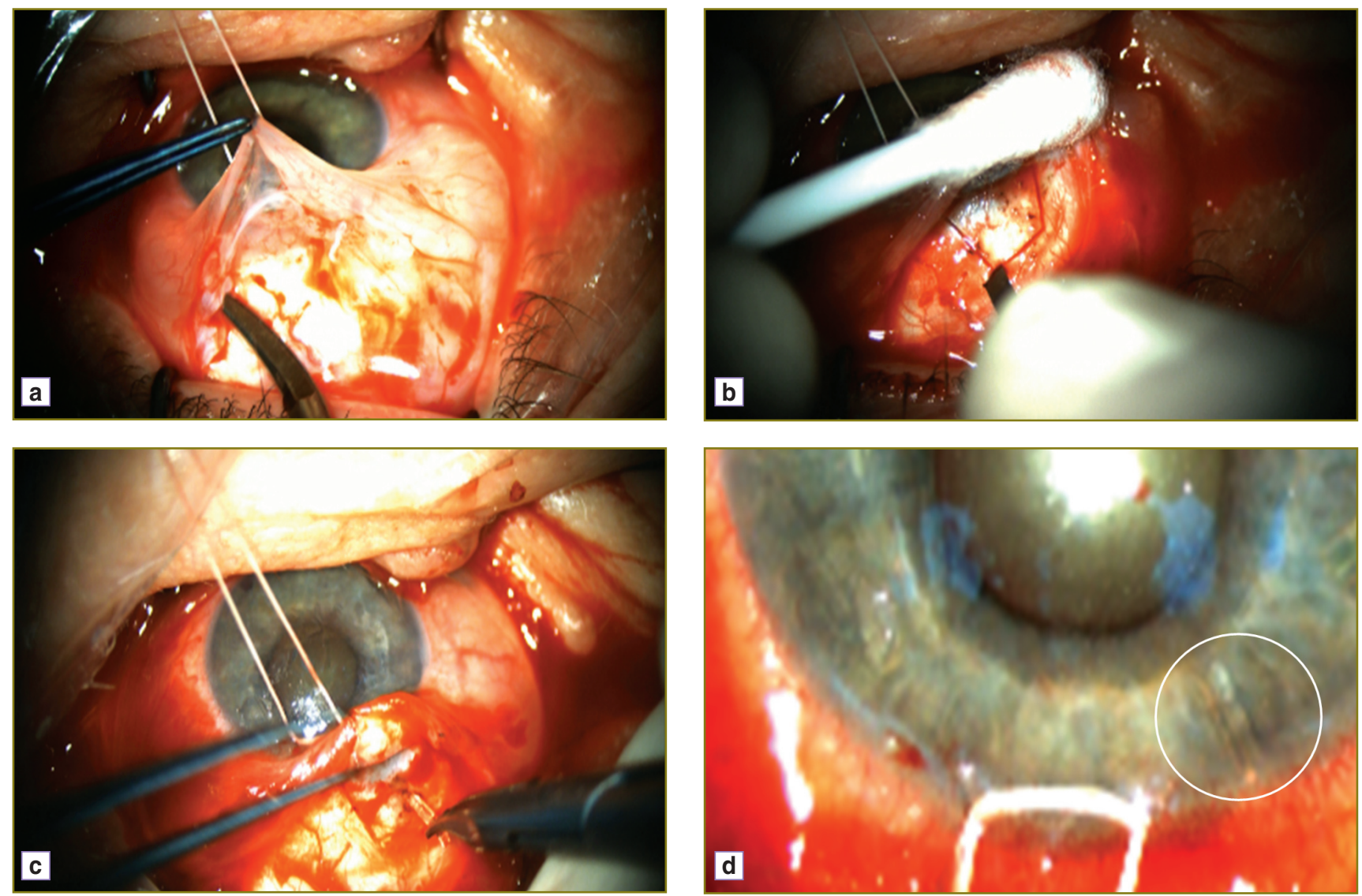

Figure 2. Stages of the operation 
computed static perimetry and optical tomography of the optic nerve disc and nerve fiber layer. Maximum followup period lasted 24 months.

This study was approved by the Ethic Committee of Nizhny Novgorod State Medical Academy and compliant with the Declaration of Helsinki (the Declaration was passed in Helsinki, Finland, June, 1964, and revised in October, 2000, Edinburg, Scotland). All patients gave written informed consent for the scientific analysis of their data.

Operative technique. A fixation suture was put on the cornea, conjunctiva incision was made $5 \mathrm{~mm}$ away from the limbus (Figure 2 (a)). After hemostasis a surface scleral flap of $1 / 2-1 / 3$ sclera thickness and about $3.5 \times 3.5 \mathrm{~mm}$ in size was cut out with its base toward the limbus (Figure 2 (b)). Then a paracenthesis was formed at the corneal part of the limbus for the period of $9 \mathrm{~h}$, and viscoelastic was introduced into the anterior chamber via the paracenthesis. Under the superficial sclera flap of the limbus transient part a hole was made with a $23 G$ needle, through which the micro-shunt was implanted with smooth branch forceps (Figure 2 (c) and (d)).

Then four sutures were placed on the sclera, an uninterrupted suture was put on the conjunctiva and Tenon's capsule.

Results and Discussion. All patients of the main and control groups were followed up from 5 months to 2 years (mean 15.2 months) to receive the remote results of the operation.

All main group patients achieved pronounced hypotensive effect on the first day after the surgery. Average IOP equaled $10.2 \mathrm{~mm} \mathrm{Hg}$. Essential reduction and stabilization of ophthalmotonus due to the outflow improvement was revealed on the basis of long-term electronic tonometry data (Table 1).

Visual functions remained unchanged. According to computed threshold perimetry data in 19 patients with preserved visual functions and its program statistical evaluation, perimetry indices remained unchanged in $56.3 \%$ of cases, $29.5 \%$ of patients showed positive dynamics, $13.3 \%$ showed insignificant decrease of light sensitivity.

Marked IOP reduction, up to mean $8.3 \mathrm{~mm} \mathrm{Hg}$, was observed in the control group on the first day after the surgery. However, in the long term (9 months after the surgery) IOP reached $24 \mathrm{~mm} \mathrm{Hg}$

Table 1 novel shunt

Table 2 number/\%)
Hydrodynamic indices in different terms of the follow-up period in open-angle glaucoma patients with the original micro-shunt

\begin{tabular}{lccccc}
\hline \multicolumn{1}{c}{ Indices } & $\begin{array}{c}\text { Before } \\
\text { surgery }\end{array}$ & $\mathbf{1}$ month & $\mathbf{3}$ months & $\mathbf{6}$ months & $\mathbf{1 5}$ months \\
$\begin{array}{l}\text { Maklakov IOP } \\
(\mathrm{mm} \mathrm{Hg})\end{array}$ & $31.18 \pm 2.63$ & $13.20 \pm 1.54$ & $17.14 \pm 1.26$ & $18.36 \pm 1.11$ & $18.42 \pm 1.9$ \\
\hline $\mathrm{P}_{0}(\mathrm{~mm} \mathrm{Hg})$ & $29.10 \pm 2.54$ & $12.65 \pm 1.02$ & $17.30 \pm 1.22$ & $17.40 \pm 1.02$ & $17.90 \pm 2.32$ \\
\hline $\mathrm{F}\left(\mathrm{mm}^{3} / \mathrm{mm} \mathrm{Hg}\right)$ & $2.86 \pm 0.51$ & $1.90 \pm 0.36$ & $2.70 \pm 0.32$ & $3.08 \pm 0.21$ & $2.72 \pm 0.35$ \\
\hline $\mathrm{C}\left(\mathrm{m}^{3} / \mathrm{min} / \mathrm{mm} \mathrm{Hg}\right)$ & $0.25 \pm 0.15$ & $0.35 \pm 0.09$ & $0.38 \pm 0.07$ & $0.39 \pm 0.09$ & $0.32 \pm 0.080$ \\
\hline $\mathrm{BC}$ & $126.40 \pm 1.35$ & $44.80 \pm 1.95$ & $45.47 \pm 2.05$ & $45.89 \pm 1.21$ & $57.90 \pm 3.05$ \\
\hline
\end{tabular}

$\mathrm{H}$ e r e: $\mathrm{P}_{0}$ is true IOP; $\mathrm{F}$ is minimum volume of aqueous humor; $\mathrm{C}$ is outflow facility coefficient; BC is Becker coefficient.

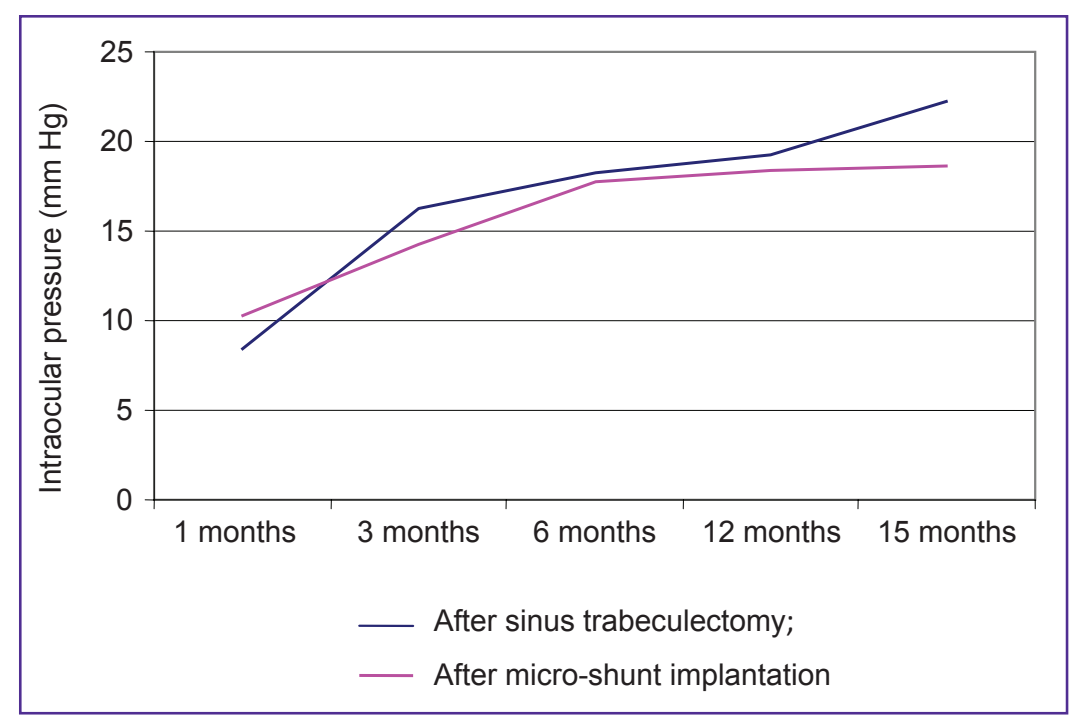

Figure 3. Dynamics of intraocular pressure using standard technique and the

The number of complications in the main and control groups (absolute

\begin{tabular}{lcc|}
\hline \multicolumn{1}{c}{ Complication type } & $\begin{array}{c}\text { After micro-shunt } \\
\text { implantation }\end{array}$ & $\begin{array}{c}\text { After } \\
\text { sinus trabeculectomy }\end{array}$ \\
\hline Hyphema & $1 / 3.2$ & $5 / 17.24$ \\
\hline $\begin{array}{l}\text { Postoperative hypotension, } \\
\text { the anterior chamber diminishing }\end{array}$ & $2 / 6.4$ & $3 / 10.3$ \\
\hline Ciliochoroidal detachment & $2 / 6.4$ & $2 / 6.9$ \\
\hline Ocular hypertension & $0 / 0$ & $1 / 3.4$ \\
\hline
\end{tabular}


micro-shunt implantation (Table 2). The total number of complications in the control group was $5(16.1 \%)$, in the main group $11(37.9 \%)$.

Conclusion. Application of the original micro-shunt in antiglaucomatous surgery provides stable hypotensive effect without additional conservative therapy throughout the course of the follow-up. As compared to sinus trabeculectomy, this surgery results in decrease of complications in the postoperative period and stabilization of visual functions, making the application of such micro-shunts a promising surgical approach to the management of open-angle glaucoma patients.

Study Finding and Conflict of Interest. This research was not financed by any sources, and there are no conflicts of interest associated with the research.

\section{References}

1. Patel S., Pasquale L.R. Glaucoma drainage devices: a review of the past, present, and future. Semin Ophthalmol 2010 Sep-Nov; 25(5-6): 265-270, http://dx.doi.org/10.3109/0 8820538.2010.518840.

2. Gedde S.J., Parrish R.K. 2nd, Budenz D.L., Heuer D.K. Update on aqueous shunts. Exp Eye Res 2011 Sep; 93(3): 284-290, http://dx.doi.org/10.1016/j.exer.2011.03.013.
3. Minckler D.S., Francis B.A., Hodapp E.A., Jampel H.D., Lin S.C., Samples J.R., Smith S.D., Singh K. Aqueous shunts in glaucoma: a report by the American Academy of Ophthalmology. Ophthalmology 2008 Jun; 115(6): 1089-1098, http://dx.doi.org/10.1016/j.ophtha.2008.03.031.

4. Kahook M.Y. Glaucoma surgery: how do we get from here to there? Middle East Afr J Ophthalmol 2009 JulSep; 16(3): 105-106, http://dx.doi.org/10.4103/0974-9233. 56218.

5. Rouse J.M., Sarkisian S.R. Jr. Mini-drainage devices: the Ex-PRESS mini-glaucoma device. In: Glaucoma surgery. Bettin P., Khaw P.T. (editors). S. Karger AG; 2012; p. 90-95, http://dx.doi.org/10.1159/000334780.

6. Gregory L., Khouri A.S., Lari H.B., Fechtner R.D. Technique for intraoperative reuse of Ex-PRESS delivery system. J Glaucoma 2013 Apr-May; 22(4): 5-6, http://dx.doi. org/10.1097/ijg.0b013e318239c1bd.

7. Khouri A.S., Khan M.N., Fechtner R.D., Vold S.D. Technique for removal of malpositioned Ex-PRESS glaucoma device. J Glaucoma 2012 Dec; 23(7): 435-436, http://dx.doi. org/10.1097/ijg.0b013e31827b1540.

8. Treushnikov V.M., Fabrikantov L.L., Nikolashin S.I., Treushnikov V.V., Molodnyakov S.P., Smetankin I.G., Maslennikova Yu.A., Andreev A.N. Mikroshunt dlya antiglaukomatoznykh operatsiy [Micro-shunt for antiglaucomatous surgery]. Patent RF 146341. 2014. 